\title{
AN ADVANCED TOOL FOR MANAGING FUZZY COMPLEX TEMPORAL INFORMATION
}

\author{
Aymen Gammoudi $^{1,2}$, Allel Hadjali ${ }^{2}$ and Boutheina Ben Yaghlane ${ }^{3}$ \\ ${ }^{1}$ LARODEC/ISGT, 92, Boulevard 9 Avril 1938, 1007 Tunis, Tunisia \\ aymen. gammoudi @ensma. fr \\ ${ }^{2}$ LIAS/ENSMA, 1 Avenue Clement Ader, 86960 Futuroscope Cedex, France \\ allel.hadjalidensma. fr \\ ${ }^{3}$ IHECT, University of Carthage, \\ IHEC-Carthage Presidence, 2016 Tunis, Tunisia \\ boutheina.yaghlanedihec.rnu.tn
}

\begin{abstract}
Many real-life applications need to handle and manage time pieces of information. Allen temporal relations are one of the most used and known formalisms for modelling and handling temporal data. This paper discusses a novel idea to introduce some kind of flexibility in defining such relations between two fuzzy time intervals. The key concept of this approach is a fuzzy tolerance relation conveniently modelled. Tolerant Allen temporal relations are then defined using the dilated and the eroded intervals of the initial fuzzy time intervals. By leveraging some particular fuzzy indices to compare two fuzzy time intervals, this extension of Allen relations is integrated in the Fuzz-TIMEE system developed in our previous works.
\end{abstract}

\section{KEYWORDS}

Temporal Relations, Fuzzy Time Intervals, Tolerance Relation, Dilation, Erosion, Temporal Databases.

\section{INTRODUCTION}

Among advanced databases we find in real world applications, temporal databases which manage temporal aspects (time, date ...) of the data they contain are often encountered. In such applications, temporal information is often perceived or expressed in an imprecise/fuzzy manner [1]. For example, periods of global revolutions are characterized by beginnings and endings naturally gradual and ill-defined (such as "well after early 20 " or "to late $30 "$ ). Unfortunately, and to the best of our knowledge, there is not much work devoted to querying/handling fuzzy/imprecise information in a temporal databases context. On the contrary, in Artificial Intelligence field, several works exist to represent and handle imprecise or uncertain information in temporal reasoning (see for instance, Dubois et al. [2], Schockaert S. and De Cock [3], Badaloni and Giacomin [4]).

Jan Zizka et al. (Eds) : CCSIT, SIPP, AISC, CMCA, SEAS, CSITEC, DaKM, PDCTA, NeCoM - 2016 pp. 97-116, 2016. @ CS \& IT-CSCP 2016

DOI : $10.5121 /$ csit.2016.60110 
As mentioned above, only very few studies have considered the issue of modeling and handling flexible queries over regular/fuzzy temporal databases. In [5] [6], an approach that integrates bipolar classifications to determine the degree of satisfaction of records, is proposed. It relies on using both positive and negative imprecise and possibly temporal preferences. But this approach is still unable to model complex temporal relationships and cannot be applied in historical temporal databases (for instance, the user may request one time period but reject a part of this period, when specifying the valid time constraint in the query). Deng et al. [7] have proposed a temporal extension to an extended ERT model to handle fuzzy numbers. They have specified a fuzzy temporal query which is an extension from the TQuel language and they have introduced the concepts of fuzzy temporal in specification expressions, selection, join and projection. Tudorie et al. [8] have proposed a fuzzy model for vague temporal terms and their implication in queries' evaluation. Unfortunately, this approach does not allow to model a large class of temporal terms (such as: just after and much before). In [9], Galindo and Medina have proposed an extension of temporal fuzzy comparators and have introduced the notion of dates in Relational Databases (RDB) by adding two extra precise attributes on dates (VST, VET). Recently, in [10] we have proposed an extension, named TSQLf, of SQLf language [11] by adding the time dimension. TSQLf language allows for expressing user queries involving fuzzy criteria on time. It is founded on the fuzzy extension of Allen temporal relations already proposed in [2].

Unfortunately, all the above approaches consider (fuzzy) temporal relations only between regular time intervals (i.e., their lower and upper bounds are crisp instants). While in real world applications, time intervals are often described by ill-defined bounds to better capture the vagueness inherent to the available pieces of time information.

This paper is a step towards dealing with that issue. It proposes an extension of Allen temporal relations to compare fuzzy time intervals. This extension relies on a particular tolerance relation that allows associating a fuzzy time interval with two nested fuzzy time intervals (i.e., the dilated and the eroded intervals). Based on these two nested intervals, in order to introduce some softness in comparing fuzzy temporal entities, tolerant Allen relations are defined. Particular fuzzy indices are used for the purpose of tolerant Allen relations computation.

The paper is structured as follows. In Section 2, we provide some background necessary to the reading of the paper and a critical related work. In section 3, tolerant Allen relations modeling and their handling are explicitly discussed. Then in section 4, we describe how we have

integrated this extension in our Fuzz-TIME system. Section 5 concludes the paper and sketches some lines for future work.

\section{BACKGROUND AND RELATED WORK}

The purpose of this section is manifold. We begin by recalling Allen temporal relation, and then we recall some fuzzy comparators of interest. Finally, we present the dilation and erosion operations on fuzzy sets. This section is mainly browsed from [2].

\subsection{Allen Temporal Relations}

Allen [12] has proposed a set of mutually exclusive primitive relations that can be applied between two temporal intervals. These relationships between events are usually denoted by before $(\prec)$, after $(>)$, meets $(\mathrm{m})$, met by (mi), overlaps (o), overlapped by (oi), during (d), 
contains (di), starts (s), started by (si), finishes (f), finished by (fi), and (三). Their meaning is illustrated in Table 1 (where $A=\left[a, a^{\prime}\right]$ and $B=\left[b, b^{\prime}\right]$ are two time intervals with $a$ and $a^{\prime}$ (respectively $b$ and $b^{\prime}$ ) represent the two bounds of $A$ (respectively $B$ ), with $a<a^{\prime}$.

\subsection{Fuzzy comparators}

In this section, we recall two fuzzy comparators expressed in terms of difference of values. Such comparators capture approximate equalities and graded inequalities.

\section{Approximate Equalities and Graded Inequalities}

An approximate equality between two values, here representing dates, modeled by a fuzzy relation $\mathrm{E}$ with membership function $\mu_{\mathrm{E}}$ (E stands for "equal"), can be defined in terms of a distance such as the absolute value of the difference. Namely,

$$
\mu_{\mathrm{E}}(\mathrm{x}, \mathrm{y})=\mu_{\mathrm{L}}(|\mathrm{x}-\mathrm{y}|)
$$

For simplicity, fuzzy sets and fuzzy relations are assumed to be defined on the real line. Approximate equality can be represented by

$$
\begin{aligned}
& \forall \mathrm{x}, \mathrm{y} \in \mathbb{R} \\
& \mu_{\mathrm{E}}(\mathrm{x}, \mathrm{y})=\mu_{\mathrm{L}}(|\mathrm{x}-\mathrm{y}|)=\max \left(0, \min \left(1, \frac{\delta+\varepsilon-|\mathrm{x}-\mathrm{y}|}{\varepsilon}\right)\right) \\
& =\left\{\begin{array}{cc}
1 & \text { if }|\mathrm{x}-\mathrm{y}| \leq \delta \\
0 & \text { if }|\mathrm{x}-\mathrm{y}|>\delta+\varepsilon \\
\frac{\delta+\varepsilon-|\mathrm{x}-\mathrm{y}|}{\varepsilon} & \text { otherwise }
\end{array}\right.
\end{aligned}
$$

\begin{tabular}{|c|c|c|c|}
\hline Relation & Inverse & Signification & $\begin{array}{l}\text { Relations between } \\
\text { bounds }\end{array}$ \\
\hline$A<B$ & $B \succ A$ & 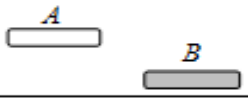 & $b>a^{\prime}$ \\
\hline$A m B$ & $B m i A$ & $\square^{A} \quad B$ & $a^{\prime}=b$ \\
\hline$A \circ B$ & $B$ oi $A$ & $\stackrel{A}{\rightleftarrows}{ }_{B}$ & $\begin{array}{c}b>a \wedge a^{\prime}>b \wedge b^{\prime}> \\
a^{\prime}\end{array}$ \\
\hline$A d B$ & $B$ di $A$ & $\frac{A}{B}$ & $a>b \wedge b^{\prime}>a^{\prime}$ \\
\hline$A \leq B$ & $B \operatorname{si} A$ & $\stackrel{A}{\longleftarrow} B$ & $a=b \wedge b^{\prime}>a^{\prime}$ \\
\hline$A f B$ & $B$ fi $A$ & $B \quad A$ & $a>b \wedge b^{\prime}=a^{\prime}$ \\
\hline$A \equiv B$ & $B \equiv A$ & $\begin{array}{c}A \\
B \\
\end{array}$ & $a=b \wedge a^{\prime}=b^{\prime}$ \\
\hline
\end{tabular}

Table 1. Allen Relations. 
where $\rho$ and $\epsilon$ are respectively positive and strictly positive parameters which affect the approximate equality. With the following intended meaning: the possible values of the difference $a-b$ are restricted by the fuzzy set $\mathrm{L}=(-\delta, \delta, \varepsilon, \varepsilon){ }^{1}$. In particular $a \mathrm{E}(0) b$ means $a=b$.

Similarly, a more or less strong inequality can be modeled by a fuzzy relation $G$ ( $G$ stands for "greater"), of the form

$$
\mu_{\mathrm{G}}(\mathrm{x}, \mathrm{y})=\mu_{\mathrm{K}}(\mathrm{x}-\mathrm{y})
$$

In the following, we take

$$
\begin{aligned}
& \forall \mathrm{x}, \mathrm{y} \in \mathbb{R} \\
& \mu_{\mathrm{G}}(\mathrm{x}, \mathrm{y})=\mu_{\mathrm{K}}(\mathrm{x}-\mathrm{y})=\max \left(0, \min \left(1, \frac{x-y-\lambda}{\rho}\right)\right) \\
& =\left\{\begin{array}{cc}
1 & \text { if } x>y+\lambda+\rho \\
0 & \text { if } x \leq y+\lambda \\
\frac{x-y-\lambda}{\rho} & \text { otherwise }
\end{array}\right.
\end{aligned}
$$

We assume $\rho>0$, i.e. G more demanding than the idea of "strictly greater" or "clearly greater". K $=(\lambda, \lambda+\rho,+\infty,+\infty)$ is a fuzzy interval which gathers all the values equal to or greater than a value fuzzily located between $\lambda$ and $\rho$. K is thus a fuzzy set of positive values with an increasing membership function. See Figure 1. According to the values of parameter $\lambda+\rho$ the modality, which indicates how much larger than $b$ is $a$, may be linguistically labelled by "Slightly", "moderately", "much". In a given context G(0) stands for '>'.

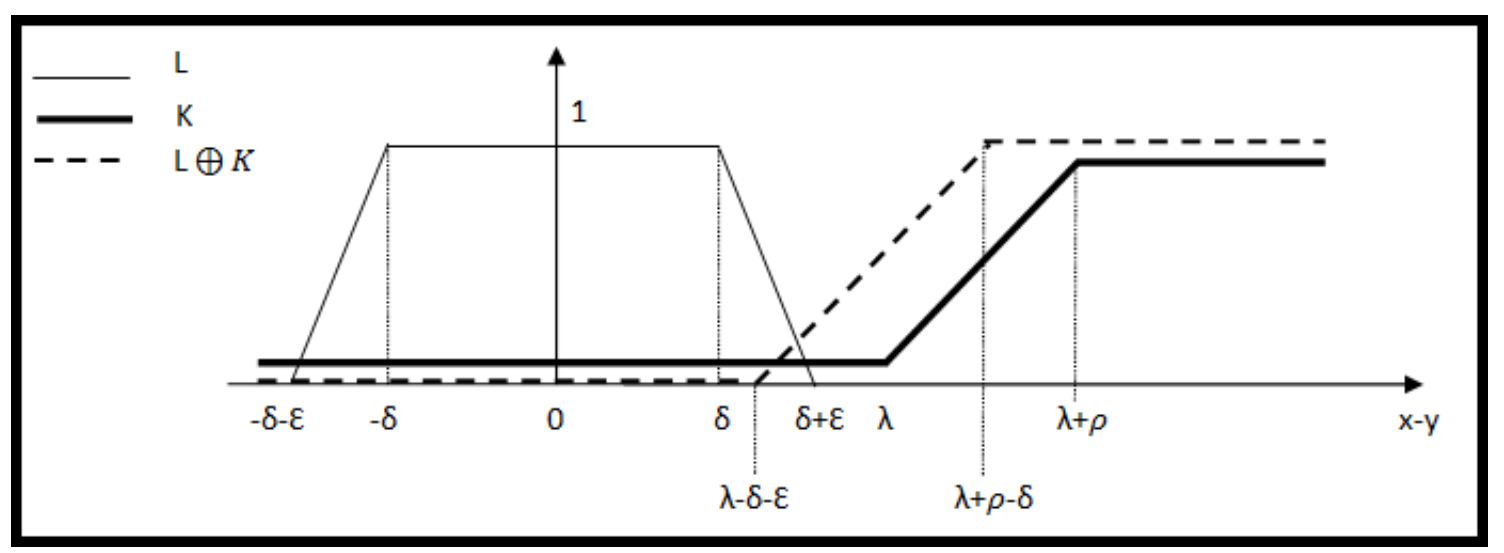

Figure 1. Modeling "approximate equality" and "graded strict inequality".

\subsection{Dilation and Erosion Operations}

Let us consider a fuzzy set $A$ representing a time interval, and an approximate equality relation $\mathrm{E}(\mathrm{L}) . A$ can be associated with a nested pair of fuzzy sets when using the parameterized relation $\mathrm{E}(\mathrm{L})$ as a tolerance relation [2]. Indeed,

\footnotetext{
${ }^{1} \mathrm{~A}=(\mathrm{A}, \mathrm{B}, \mathrm{a}, \mathrm{b})$ stands for the trapezoidal membership function (t.m.f.) of the fuzzy set A where [A, B] (resp. $[\mathrm{A}-\mathrm{a}, \mathrm{B}+\mathrm{b}])$ is the core (resp. support).
} 
* one can build a fuzzy set of temporal instants close to $A$ such that $A \subseteq A^{L}$. This is the dilation operation,

* one can build a fuzzy set of temporal instants close to $A$ such that $A_{L} \subseteq \mathrm{A}$. This is the erosion operation.

\subsubsection{Dilation operation}

Dilating the fuzzy set of temporal instants $A$ by $L$ will provide a fuzzy set $A^{L}$ defined by

$$
\begin{aligned}
\mu_{A^{L}}(r) & =\sup _{s} \min \left(\mu_{E[L]}(s, r), \mu_{A}(s)\right) \\
& =\sup _{s} \min \left(\mu_{L}(r-s), \mu_{A}(s)\right) \\
& =\mu_{A \oplus L}(r)
\end{aligned}
$$

Hence,

$$
\mathrm{A}^{\mathrm{L}}=\mathrm{A} \oplus \mathrm{L}
$$

where $\oplus$ is the addition operation extended to fuzzy sets [13]. $A^{\mathrm{L}}$ gathers the elements of $A$ and the elements outside A which are somewhat close to an element in A. See Figure 2.

One can easily check that the fuzzy set of temporal instants $\mathrm{A}^{\mathrm{L}}$ is less restrictive than $A$, but still semantically close to $A$. Thus, $\mathrm{A}^{\mathrm{L}}$ can be viewed as a relaxed variant of $A$. In terms of t.m.f., if $A$ $=\left(\mathrm{a}, \mathrm{a}^{\prime}, \alpha, \alpha^{\prime}\right)^{2}$ and $\mathrm{L}=(-\delta, \delta, \epsilon, \epsilon)$ then $\mathrm{A}^{\mathrm{L}}=\left(\mathrm{a}-\delta, \mathrm{a}^{\prime}+\delta, \alpha+\epsilon, \alpha^{\prime}+\epsilon\right)$, see Figure 2.

\section{Example:}

If $A=(15,19,2,1)$ and $L=(-1,1,0.5,0.5)$ then

$$
A^{L}=(14,20,2.5,1.5)
$$

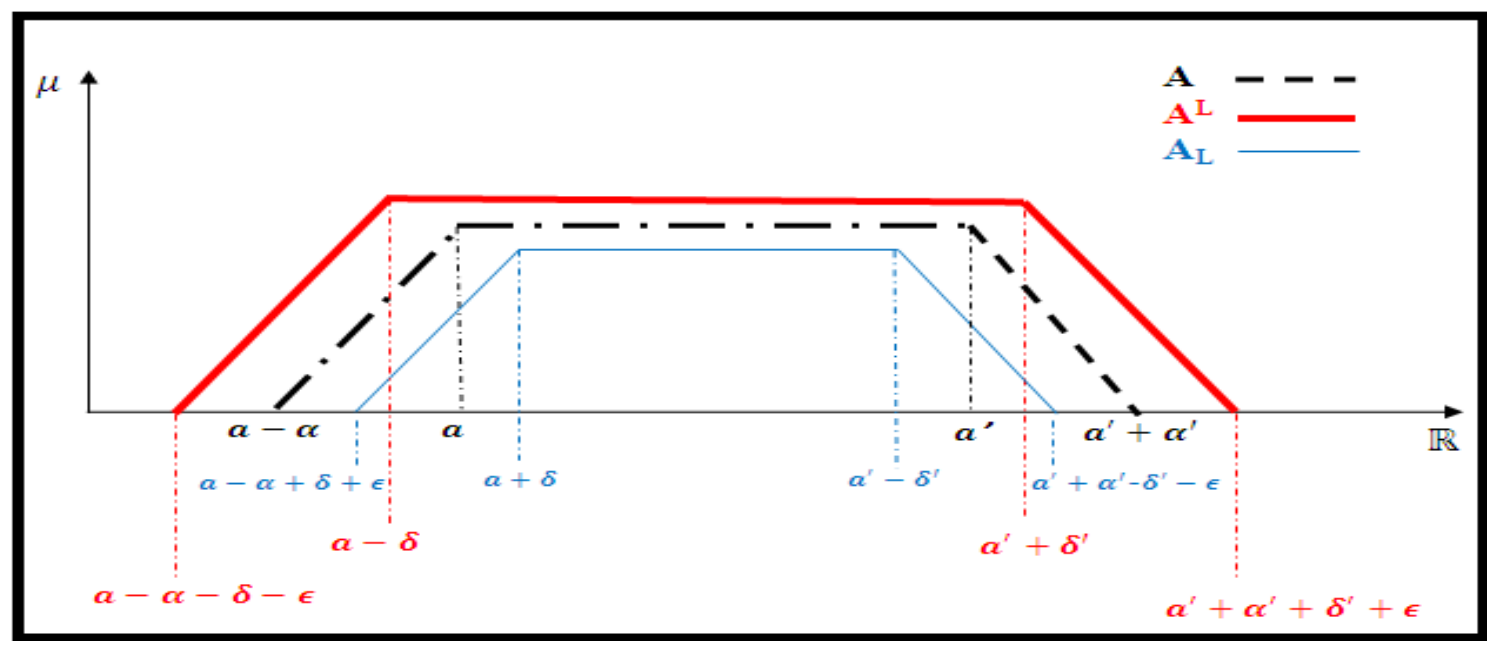

Figure 2. Dilated and eroded time intervals of a fuzzy set of temporal instants $A$.

\footnotetext{
${ }^{2}$ with [a, a'] (resp. [a- $\left.\left.\alpha, a^{\prime}+\alpha^{\prime}\right]\right)$ represents the core (resp. support) of $A$.
} 


\subsubsection{Erosion operation}

Let $\mathrm{L} \oplus \mathrm{X}=\mathrm{A}$ be an equation where $X$ is the unknown variable. Solving this equation has extensively been discussed in [14]. It has been demonstrated that the greatest solution of this equation is given by $\bar{X}=A \ominus(-L)=A \ominus L$ since $L=-L$ and where $\ominus$ is the extended Minkowski subtraction defined by [11]:

$$
\mu_{\mathrm{A} \ominus \mathrm{L}}(\mathrm{r})=\inf _{\mathrm{s}}\left(\mu_{\mathrm{L}}(\mathrm{r}-\mathrm{s}) \Rightarrow_{\mathbb{T}} \mu_{\mathrm{A}}(\mathrm{s})\right)
$$

where $\mathbb{T}$ a t-norm, and $\Rightarrow_{\mathbb{T}}$ is the R-implication induced by $\mathbb{T}$ and defined by $\Rightarrow_{\mathbb{T}}(u, v)=$ $\sup \{\lambda \in[0,1], \mathbb{T}(u, \lambda) \leq v\}$ for $u, v \in[0,1]$. We make use of the same t-norm $\mathbb{T}(=\min )$ as in the dilation operation which implies that $\Rightarrow_{\mathbb{T}}$ is the so-colled Gödel implication.

Let $(E[L])_{r}=\left\{s, \mu_{E[L]}(s, r)>0\right\}$ be the set of elements that are close to $r$ in the sense of $E[L]$. Then, the above expression can be interpreted as the degree of inclusion of $(\mathrm{E}[\mathrm{Z}])_{\mathrm{r}}$ in $A$. This means that $r$ belongs to A $\ominus \mathrm{L}$ all the elements $s$ that are close to $r$ are $A$. Hence, the inclusion A $\ominus \mathrm{L} \subseteq \mathrm{A}$ holds. This operation is very useful in natural language to intensify the meaning of vague terms. Now, eroding the fuzzy set $A$ by $L$ results in the fuzzy set $A_{\mathrm{L}}$ defined by

$\mathrm{A}_{\mathrm{L}}=\mathrm{A} \ominus \mathrm{L}$.

The fuzzy set $\mathrm{A}_{\mathrm{L}}$ is more precise than the original fuzzy set $A$ but it still remains not too far from $A$ semantically speaking. If $\mathrm{A}=\left(\mathrm{a}, \mathrm{a}^{\prime}, \alpha, \alpha^{\prime}\right)$ and $\mathrm{L}=(-\delta, \delta, \epsilon, \epsilon)$ then

$\mathrm{A}_{\mathrm{L}}=\mathrm{A} \ominus \mathrm{L}=\left(\mathrm{a}+\delta, \mathrm{a}^{\prime}-\delta, \alpha-\epsilon, \alpha^{\prime}-\epsilon\right)$ provide that $\alpha \geq \epsilon$ and $\alpha^{\prime} \geq \epsilon$. Figure 2 illustrates this operation.

\section{Example:}

If $A=(15,19,2,1)$ and $L=(-1,1,0.5,0.5)$ then

$$
A_{L}=(16,18,1.5,0.5)
$$

In the crisp case, $\mathrm{A} \ominus \mathrm{L}=\left[\mathrm{a}, \mathrm{a}^{\prime}\right] \ominus\left[-\delta, \delta^{\prime}\right]=\left[\mathrm{a}+\delta, \mathrm{a}^{\prime}-\delta^{\prime}\right]$ (while $\mathrm{A} \oplus \mathrm{Z}=\left[\mathrm{a}-\delta, \mathrm{a}^{\prime}+\delta^{\prime}\right]$ ). One can easily check that the following proposition holds:

Proposition 1. Using the t.m.f. of $\mathrm{A}^{\mathrm{L}}$ and $\mathrm{A}_{\mathrm{L}}$ given above, we have:

- $\quad\left(\mathrm{A}^{\mathrm{L}}\right)_{\mathrm{L}}=\left(\mathrm{A}_{\mathrm{L}}\right)^{\mathrm{L}}=\mathrm{A}$

- $\left(\mathrm{A}^{\mathrm{L}}\right)^{\mathrm{L}}=\mathrm{A} \oplus 2 \mathrm{~L}$

- $\left(A_{L}\right)_{L}=A \ominus 2 L$

\subsection{Related Work}

Temporal information is often perceived or expressed in a vague and imprecise manner. Here we discuss some works related to the modeling and handling of imperfections in time both in Artificial Intelligence and Databases fields.

The treatment of imprecise or uncertain information in temporal reasoning has been addressed for a longtime. Dubois and Prade in [15] discuss the approximate reasoning on fuzzy dates and fuzzy 
intervals in the framework of possibility theory. Guesgen et al. [16] propose fuzzy Allen relations viewed as fuzzy sets of ordinary Allen relationship taking into account a neighborhood structure.

Fuzzy sets, which play a key role in the modeling of flexible constraints, have also been used in different approaches based on constraints for temporal reasoning. Qian and $\mathrm{Lu}$ [17] have studied several propagation strategies for the treatment of fuzzy rules temporal networks. Barro et al. [18] have proposed a generalization based on fuzzy sets of time constraint and used possibility measures to verify the consistency's degree of a fuzzy temporal constraint network. Godo and Vila [19] have defined a temporal logic approximated based on the integration of fuzzy constraints in a logical language. The inference system is based on specific rules treating fuzzy constraints and proposals degrees of certainty. Dubois et al. [20] have proposed a possibilistic temporal logic that a formula which is associated with a fuzzy set of dates when the formula is more or less certainly true.

On the other hand, only few works have been proposed for dealing with imperfect data in databases. Billiet et al. [5] have proposed an approach that integrates bipolar classifications to determine the degree of satisfaction of records by using both positive and negative imprecise and possibly temporal preferences. But this approach is still unable to model complex temporal relationships and not applied in historical temporal databases (for instance, the user may request one time period but reject a part of this period, when specifying the valid time constraint in the query). Tudorie et al. [8] have proposed a fuzzy model for vague temporal terms and their implication in queries' evaluation. Unfortunately, this approach does not allow to model a large number of temporal terms (such as: just after and much before). Galindo and Medina [9] have proposed an extension of temporal fuzzy comparators and have introduced the notion of dates in Relational Databases (RDB) by adding two extra precise attributes on dates (VST, VET). The most disadvantage of this approach that cannot support some sophisticated queries that need a step of reasoning before processing. However, some comparators might not be in full agreement with the intuitive semantics underlying the notion of the temporal relations that refer to.

However, in [10] we have proposed an extension, named TSQLf, of $S Q L f$ language [11] by the addition of the dimension time. TSQLf language allows for expressing user queries involving fuzzy criteria on time. It is founded on the fuzzy extension of Allen temporal relations already proposed in [2]. Recently, in [21] we have proposed a first step to introduce some flexibility in defining such relations between two fuzzy time intervals. This idea presents an extension of Allen temporal relations based on a particular tolerance relation that allows associating a fuzzy time interval with two nested intervals (i.e., the dilated and the eroded intervals).

Unfortunately, all the above approaches consider (fuzzy) temporal relations only between regular time intervals (i.e., their lower and upper bounds are crisp instants). While in real world applications, time intervals are often described by ill-defined bounds to better capture the vagueness inherent to the available pieces of time information. In this context (i.e., bounds of temporal intervals are ill-defined), not much work exist in the literature. Except, the works done by Nagypal and Motik [22], Ohlbach [23] and Schockaert et al. [3]. Nagypal and Motik [22] have defined a temporal model based on fuzzy sets. This model extends Allen relations with fuzzy time intervals (ITFs). An ITF means a temporal interval with bounds defined in an imprecise way (for example, "the period from the late 20 s to the early $30 \mathrm{~s}$ " is an ITF with the following semantics $(1928,1933,2,2))$. Nagypal and Motik have introduced a set of auxiliary operators on intervals such as, for example, the operator taking an interval $I$ and built intervals containing all 
instants which are before initial time $I$. Then, fuzzy counterparts of these operators have been defined on the ITFs. Extended Allen relations with ITFs were introduced using the fuzzy operators. Note that the composition of these relations was not discussed by the authors. Schockaert et al. [3] also proposed a generalization of Allen relations with ITFs. This generalization allows handling classical relations between imprecise events (such as, "Roosevelt died before the start of the Cold War"), and also imprecise nature relations (such as, "Roosevelt died just before the start of the Cold War "). The key notion used in this approach is the concept of fuzzy orders on time (as, for example, the fuzzy order that expresses how a moment $a$ is much smaller than a moment $b$ ). These orders represented by parameterized fuzzy relations are applied to the gradual bounds ITFs to define, for example, the degree $b b^{\ll<}(A, B)$ (expressing how the beginning of an ITF $A$, defined in an imprecise manner, is before the end of an ITF $B$ defined in an imprecise way as well). In [4], Badaloni and Giacomin have developed a fuzzy extension of the algebra of intervals, named $\mathrm{IA}^{\text {fuz }}$ where degrees of preference (belonging to $[0,1]$ ) are attached to each atomic relation between two classical time intervals.

\section{TOLERANT ALLEN RELATIONS}

The purpose of this section is twofold. We start by modeling tolerant Allen relations based on dilation and erosion operations. Then, we present the comparing indices of two fuzzy intervals to compute to what extent a tolerant Allen relation is satisfied.

\subsection{Modeling}

Using the dilatation and erosion operations defined above, we can provide the basis for defining a tolerance-based extension of Allen relations. For instance, the tolerance-based temporal relation corresponding to meet Allen relation writes:

\section{A toler-meets $(\mathrm{L}) B$ would correspond to $\mathrm{A}_{\mathrm{L}}$ before $\mathrm{B}_{\mathrm{L}}$ and $\mathrm{A}^{\mathrm{L}}$ overlaps $\mathrm{B}^{\mathrm{L}}$}

The statement $A$ toler-meets(L) $B$ means that the temporal relation between the two (crisp/fuzzy) temporal intervals $A$ and $B$ is perceived as a variant of meet relation thanks to some tolerance expressed by the indicator $L$. This is a human perception which is often encountered in real world applications (such as in managing historical temporal data, planning and scheduling, natural language understanding, etc.).

The toler-meet relation gathers a class of Allen relations (i.e., before and overlaps) applied on the eroded and dilated time intervals corresponding to the original time intervals $A$ and $B$. This boils down to compute the traditional Allen relations, before and overlaps, on fuzzy temporal intervals $A^{L}$ and $A_{L}$ (since $A^{L}$ and $A_{L}$ are fuzzy sets as shown in the previous subsection).

Let $\mathrm{A}=\left(\mathrm{a}, \mathrm{a}^{\prime}, \alpha, \alpha^{\prime}\right)$ be a fuzzy time interval with $\widetilde{\mathrm{a}}=(\mathrm{a}, \mathrm{a}, \alpha, 0)$ and $\widetilde{\mathrm{a}}^{\prime}=\left(\mathrm{a}^{\prime}, \mathrm{a}^{\prime}, 0, \alpha^{\prime}\right)$ the two fuzzy bounds of validity of $A$. One can write $\mathrm{A}=\left(\widetilde{\mathrm{a}}, \mathrm{a}, \mathrm{a}^{\prime}, \tilde{\mathrm{a}}^{\prime}\right)$. Under these forms:

- $\mathrm{A}^{\mathrm{L}}$ writes $\left(\mathrm{a}-\delta, \mathrm{a}^{\prime}+\delta, \tilde{\mathrm{a}}^{(\mathrm{L})}, \tilde{\mathrm{a}}^{\prime(\mathrm{L})}\right)$ where $\tilde{\mathrm{a}}^{(\mathrm{L})}=(\mathrm{a}-\delta, \mathrm{a}-\delta, \alpha+\epsilon, 0) \quad$ and $\tilde{a}^{\prime}(\mathrm{L})=\left(\mathrm{a}^{\prime}+\delta, \mathrm{a}^{\prime}+\delta, 0, \alpha^{\prime}+\epsilon\right)$.

- $\mathrm{A}_{\mathrm{L}}$ writes $\left(\mathrm{a}+\delta, \mathrm{a}^{\prime}-\delta, \tilde{\mathrm{a}}_{(\mathrm{L})}, \widetilde{\mathrm{a}}_{(\mathrm{L})}^{\prime}\right)$ where $\tilde{\mathrm{a}}_{(\mathrm{L})}=(\mathrm{a}+\delta, \mathrm{a}+\delta, \alpha-\epsilon, 0)$ and $\tilde{\mathrm{a}}_{(\mathrm{L})}^{\prime}=\left(\mathrm{a}^{\prime}-\delta, \mathrm{a}^{\prime}-\delta, 0, \alpha^{\prime}-\epsilon\right)$. 


\section{Example:}

Let $A$ a fuzzy temporal interval representing the period from the early 20 until the end of 20 . It is easier to see that $A$ can writes $\mathrm{A}=\left(\tilde{a}, \tilde{a}^{\prime}, \alpha, \alpha\right)$.

With $\tilde{a}=(1920,1920,3,0)$ and $\tilde{a}^{\prime}=(1930,1930,0,2)$.

Given that $\alpha=3, \alpha^{\prime}=2$ and $L=(-3,3,1,1)$.

Then

$A^{L}=\left(1917,1933, \tilde{a}^{(L)}, \tilde{a}^{\prime(L)}\right)$ where $\tilde{a}^{(L)}=(1917,1917,4,0)$ and $\tilde{a}^{\prime(L)}=(1933,1933,0,3)$.

And

$A_{L}=\left(1923,1927, \tilde{a}_{(L)}, \tilde{a}_{(L)}^{\prime}\right)$ where $\tilde{a}_{(L)}=(1923,1923,2,0)$ and $\tilde{a}_{(L)}^{\prime}=(1927,1927,0,1)$.

In a similar way, the tolerant counterparts of all Allen relations write:

- A toler-meets $(\mathrm{L}) B$ as $\mathrm{A}_{\mathrm{L}}$ before $\mathrm{B}_{\mathrm{L}}$ and $\mathrm{A}^{\mathrm{L}}$ overlaps $\mathrm{B}^{\mathrm{L}}$.

- A toler-before $(\mathrm{L}) B$ as $\mathrm{A}^{\mathrm{L}}$ toler-meets $(\mathrm{L}) \mathrm{B}^{\mathrm{L}}$.

- A toler-overlaps (L) $B$ as $\mathrm{A}_{\mathrm{L}}$ toler-meets $\mathrm{B}_{\mathrm{L}}$.

- A toler-during (L) $B$ as $\mathrm{A}^{\mathrm{L}}$ toler-equals $\mathrm{B}_{\mathrm{L}}$.

- A toler-starts $(\mathrm{L}) B$ as $\mathrm{A}_{\mathrm{L}}$ during $\mathrm{B}^{\mathrm{L}}$ and $\mathrm{A}^{\mathrm{L}}$ overlaps $\mathrm{B}_{\mathrm{L}}$.

- A toler-finishes (L) $B$ as $\mathrm{A}^{\mathrm{L}}$ overlapped_by $\mathrm{B}_{\mathrm{L}} \wedge \mathrm{A}_{\mathrm{L}}$ during $\mathrm{B}^{\mathrm{L}}$.

- A toler-equals $(\mathrm{L}) B$ as $\mathrm{A}^{\mathrm{L}}$ contains $\mathrm{B}_{\mathrm{L}} \wedge \mathrm{A}_{\mathrm{L}}$ during $\mathrm{B}^{\mathrm{L}}$.

\subsection{Computation}

In this section, firstly, we recall the comparing indices of two fuzzy intervals proposed by Dubois and Prade in [24].

Let two fuzzy time intervals $M$ and $N$ expressed by quadruples of the form $\left(\mathrm{m}_{1}, \mathrm{~m}_{2}, \alpha_{1}, \alpha_{2}\right)$ and $\left(\mathrm{n}_{1}, \mathrm{n}_{2}, \beta_{1}, \beta_{2}\right)$ respectively. Basically, there are four indices to interpret how $M$ is greater than $N$ (see Figure 3).

$$
\begin{aligned}
& d(M>N)=\inf _{x, y}\left\{\max \left(1-\mu_{M}(x), 1-\mu_{N}(y)\right): x \leq y\right\} \\
& d\left(M>^{+} N\right)=\inf _{x} \sup _{y}\left\{\max \left(1-\mu_{M}(x), \mu_{N}(y)\right): x \geq y\right\} \\
& d\left(M>^{-} N\right)=\sup _{x} \inf _{y}\left\{\max \left(\mu_{M}(x), 1-\mu_{N}(y)\right): x<y\right\} \\
& d(M \geqslant N)=\sup _{x, y}\left\{\min \left(\mu_{M}(x), \mu_{N}(y)\right): x \geq y\right\}
\end{aligned}
$$




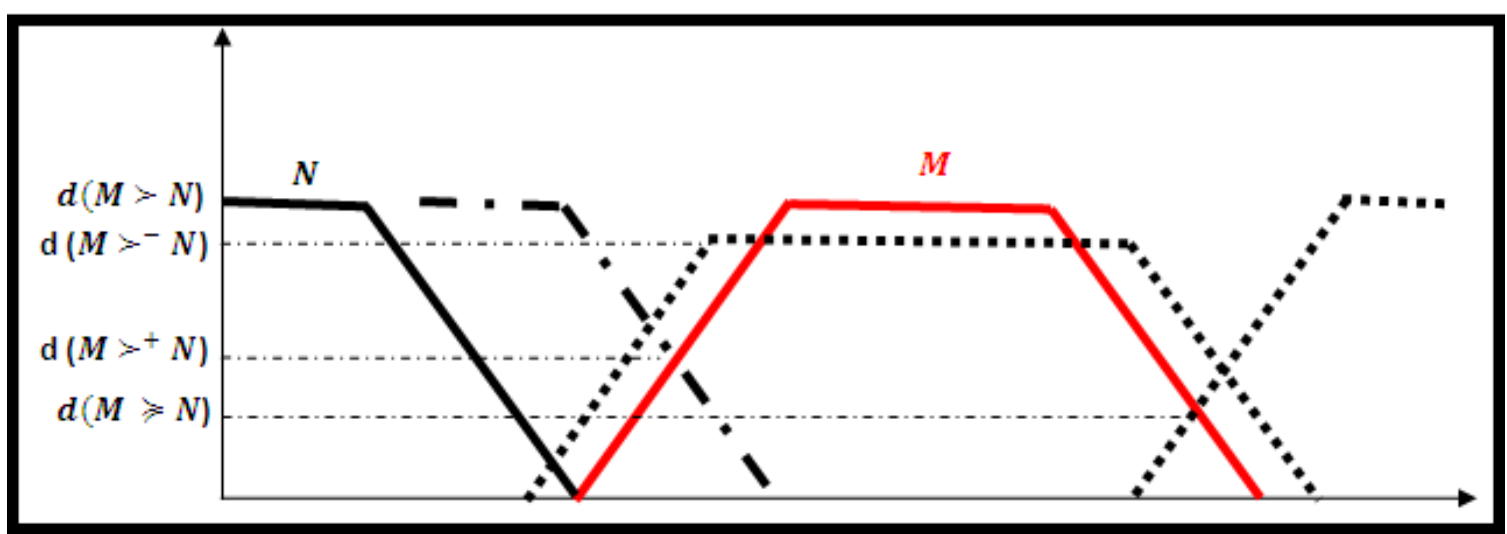

Figure 3. Possibilistic indices of fuzzy intervals comparisons.

Equation (5) expresses the certainty that $x$ is greater than $N$, knowing that $x$ is $M$. This means that $M$ is necessarily greater than $N$. It can be expressed on the basis of a necessity degree of the proposal that $M$ is strictly greater than $N$ as follows:

$\left.\left.\aleph_{M}(] N,+\infty\right)\right)=1-\sup _{x \leq y} \min \left(\mu_{M}(x), \mu_{N}(y)\right)$

Equation (9) refers to the degree of inclusion of the fuzzy set $M$ in $] N,+\infty$ ). Knowing that;

$$
\left.\left.\aleph_{\mathrm{M}}(] \mathrm{N},+\infty\right)\right)=\operatorname{Ness}(\mathrm{x}>N \mid x \text { is } M)
$$

Equation (6) expresses the certainty that $x$ is greater or equal to $N$, knowing that $x$ is $M$. It can be expressed on the basis of a necessity degree of the proposal that $M$ is greater than or equal to $N$ as follows:

$\aleph_{M}([N,+\infty))=\inf _{x} \sup _{y: y \leq x} \max \left(1-\mu_{M}(x), \mu_{N}(y)\right)$

Equation (10) refers to the degree of inclusion of the fuzzy set $M$ in $[\mathrm{N},+\infty)$. Knowing that

$$
\aleph_{M}([N,+\infty))=\operatorname{Ness}(x \geq N \mid x \text { is } M)
$$

Equation (7) expresses the possibility that $x$ is greater than $N$, knowing that $x$ is $M$. It can be expressed on the basis of a possibility degree of the proposal that $M$ is strictly greater than $N$ as follows:

$\left.\left.\Pi_{\mathrm{M}}(] \mathrm{N},+\infty\right)\right)=\sup _{\mathrm{x}} \inf _{\mathrm{y}: \mathrm{y} \geq \mathrm{x}} \min \left(\mu_{\mathrm{M}}(\mathrm{x}), 1-\mu_{\mathrm{N}}(\mathrm{y})\right)$

Equation (11) refers to the degree of nonemptiness of the fuzzy set $M \cap] N,+\infty$ ) of numbers strictly greater than $N$, given that they are restricted by $M$. Knowing that:

$$
\left.\left.\prod_{\mathrm{M}}(] \mathrm{N},+\infty\right)\right)=\text { Poss }(\mathrm{x}>N \mid x \text { is } M
$$

Equation (8) expresses the possibility that $x$ is greater or equal to $N$, knowing that $x$ is $M$. It can be expressed on the basis of a possibility degree of the proposal that $M$ is greater than or equal to $N$ as follows: 


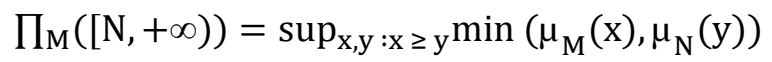

Equation (12) refers to the degree of nonemptiness of the fuzzy set $\mathrm{M} \cap[\mathrm{N},+\infty)$ of numbers greater than or equal to $N$, given that they are restricted by $M$. Knowing that:

$$
\prod_{M}([N,+\infty))=\text { Poss }(x \geq N \mid x \text { is } M)
$$

Given these degrees of comparison between two fuzzy time intervals, we can use equation (5) redefined in terms of a degree of necessity by the equation (9) to assess the extent to which a fuzzy time interval $A$ is greater than another fuzzy time interval $B$ (see Figure 4 ), denoted by $\mathrm{d}(\mathrm{A}>\mathrm{B})$ (with $A=\left(\mathrm{a}_{1}, \mathrm{a}_{2}, \alpha_{1}, \alpha_{2}\right)$ and $\left.\mathrm{B}=\left(\mathrm{b}_{1}, \mathrm{~b}_{2}, \beta_{1}, \beta_{2}\right)\right)$ as follows;

$$
\begin{aligned}
d(A>B)=1-\sup _{x \leq y} & \min \left(\mu_{A}(x), \mu_{B}(y)\right) \\
= & \left\{\begin{array}{cc}
1 & \text { if } a_{1}-\alpha_{1} \geq b_{2}+\beta_{2} \\
1-\rho & \text { if } a_{1}-\alpha_{1}<b_{2}+\beta_{2} \text { and } a_{1}>b_{2} \\
0 & \text { otherwise }
\end{array}\right.
\end{aligned}
$$

with $\rho=\frac{x-\left(a_{1}-\alpha_{1}\right)}{\alpha_{1}}$ and $x=\frac{b_{2} \alpha_{1}+a_{1}}{1+\alpha_{1}}$

To illustrate formula (13), let us consider the following example (where $A=[25 / 10 / 2015$, 28/10/2015, 1, 1] that expresses time around October 25 and October 28):

Case 1: $B=[19 / 10 / 2015,20 / 10 / 2015,2,2]$

$$
\begin{gathered}
\mathrm{a}_{1}-\alpha_{1}>\mathrm{b}_{2}+\beta_{2} \rightarrow 24 / 07 / 2015>20 / 07 / 2015 \text { then } \\
\mathrm{d}(\mathrm{A}>\mathrm{B})=1
\end{gathered}
$$

Case 2: $B=[19 / 10 / 2015,24 / 10 / 2015,2,2]$

$$
\begin{aligned}
& a_{1}-\alpha_{1}<b_{2}+\beta_{2} \rightarrow 24 / 07 / 2015<26 / 07 / 2015 \text { and } \\
& a_{1}>b_{2} \rightarrow 25 / 07 / 2015>24 / 07 / 2015 \text { then } \\
& \quad d(A>B)=1-\rho=1-\frac{b_{2}-a_{1}+1+\alpha_{1}}{1+\alpha_{1}}=0,5
\end{aligned}
$$

Case 3: $B=[19 / 10 / 2015,26 / 10 / 2015,2,2]$

$$
\begin{gathered}
\mathrm{a}_{1}-\alpha_{1}<\mathrm{b}_{2}+\beta_{2} \rightarrow 24 / 07 / 2015<27 / 07 / 2015 \text { and } \\
\mathrm{a}_{1}<\mathrm{b}_{2} \rightarrow 25 / 10 / 2015<26 / 10 / 2015 \text { then } \\
\mathrm{d}(\mathrm{A}>\mathrm{B})=0
\end{gathered}
$$




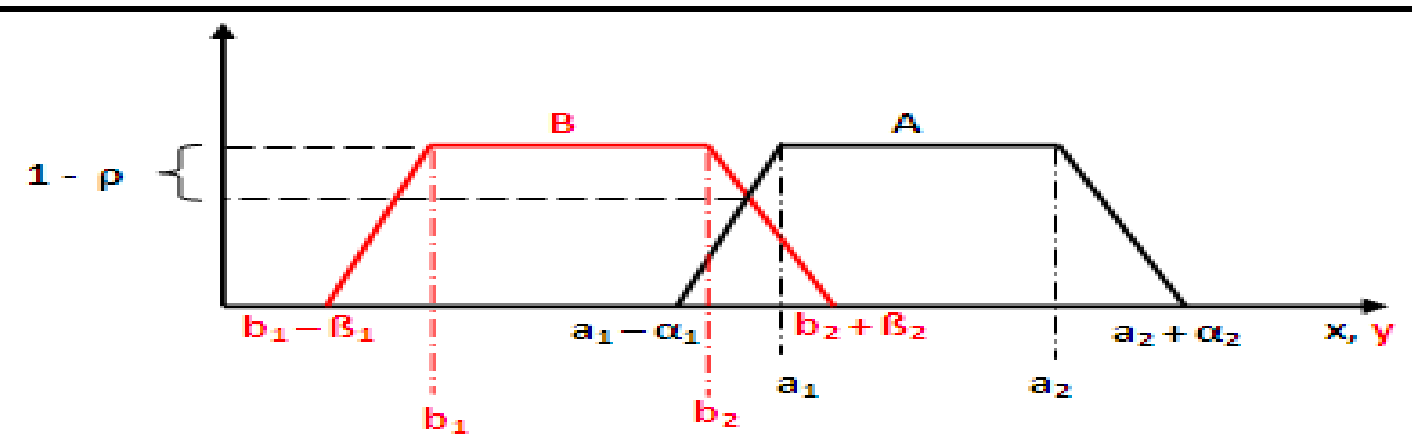

Figure 4. Comparison index $d(A>B)$.

Using the formula (13), we define in Table 2 a way to calculate the degree of tolerant Allen relations. We have used this formula because we need to be sure that an interval $A$ is greater than another $B$. This means that $A$ is necessarily greater than $B$.

Table 2. Tolerant Allen Relations (where $\left.d\left(\tilde{b}_{L}>\tilde{a}_{L}^{\prime}\right)=1-\sup _{x \leq y} \min \left(\mu_{\widetilde{b}_{L}}(x), \mu_{\tilde{a}^{\prime}}(y)\right)\right)$.

\begin{tabular}{|c|c|c|}
\hline $\begin{array}{l}\text { Tolerant Allen } \\
\text { Relation }\end{array}$ & Interpretation & Definition \\
\hline$A$ toler-meets $(\mathrm{L}) B$ & $\begin{array}{l}A_{L} \text { before } B_{L} \wedge \\
A^{L} \text { overlaps } B^{L}\end{array}$ & $\begin{array}{l}\operatorname{Min}\left(d\left(\tilde{b}_{\mathrm{L}}>\tilde{\mathrm{a}}_{\mathrm{L}}^{\prime}\right), \mathrm{d}\left(\tilde{\mathrm{b}}^{\mathrm{L}}>\tilde{\mathrm{a}}^{\mathrm{L}}\right),\right. \\
\left.\mathrm{d}\left(\tilde{\mathrm{a}}^{\prime \mathrm{L}}>\tilde{\mathrm{b}}^{\mathrm{L}}\right), \mathrm{d}\left(\tilde{\mathrm{b}}^{\prime \mathrm{L}}>\tilde{\mathrm{a}}^{\prime \mathrm{L}}\right)\right)\end{array}$ \\
\hline A toler-before $(\mathrm{L}) B$ & $A^{L}$ toler-meets $B^{L}$ & $\begin{array}{c}\operatorname{Min}\left(\mathrm{d}\left(\tilde{\mathrm{b}}>\tilde{\mathrm{a}}^{\prime}\right), \mathrm{d}\left(\tilde{\mathrm{b}}^{2 \mathrm{~L}}>\tilde{\mathrm{a}}^{2 \mathrm{~L}}\right),\right. \\
\left.\mathrm{d}\left(\tilde{\mathrm{b}}^{\prime 2 \mathrm{~L}}>\tilde{\mathrm{a}}^{\prime 2 \mathrm{~L}}\right), \mathrm{d}\left(\tilde{\mathrm{a}}^{\prime 2 \mathrm{~L}}>\tilde{\mathrm{b}}^{2 \mathrm{~L}}\right)\right)\end{array}$ \\
\hline A toler-overlaps $(\mathrm{L}) B$ & $A_{L}$ toler-meets $B_{L}$ & $\begin{array}{c}\operatorname{Min}\left(d\left(\tilde{b}_{2 L}>\tilde{a}_{2 L}^{\prime}\right), d(\tilde{b}>\tilde{a})\right. \\
\left.d\left(\tilde{a}^{\prime}>\tilde{b}\right), d\left(\tilde{b}^{\prime}>\tilde{a}^{\prime}\right)\right)\end{array}$ \\
\hline A toler-during $(\mathrm{L}) B$ & $\mathrm{~A}^{\mathrm{L}}$ toler-equals $\mathrm{B}_{\mathrm{L}}$ & $\begin{array}{c}\operatorname{Min}\left(\mathrm{d}\left(\tilde{\mathrm{b}}_{2 \mathrm{~L}}>\tilde{\mathrm{a}}^{2 \mathrm{~L}}\right), \mathrm{d}\left(\tilde{\mathrm{a}}^{\prime 2 \mathrm{~L}}>\tilde{\mathrm{b}}_{2 \mathrm{~L}}^{\prime}\right)\right. \\
\left.\mathrm{d}(\tilde{\mathrm{a}}>\tilde{\mathrm{b}}), \mathrm{d}\left(\tilde{\mathrm{b}}^{\prime}>\tilde{\mathrm{a}}^{\prime}\right)\right)\end{array}$ \\
\hline$A$ toler-starts $(\mathrm{L}) B$ & $\begin{array}{l}A_{L} \text { during } B^{L} \wedge \\
A^{L} \text { overlaps } B_{L}\end{array}$ & $\begin{array}{l}\operatorname{Min}\left(d\left(\tilde{a}_{L}>\tilde{b}^{L}\right), d\left(\tilde{b}^{\prime L}>\tilde{a}_{L}^{\prime}\right),\right. \\
\left.d\left(\tilde{b}_{L}>\tilde{a}^{L}\right), d\left(\tilde{a}^{\prime L}>\tilde{b}_{L}\right), d\left(\widetilde{b}_{L}^{\prime}>\tilde{a}^{\prime L}\right)\right)\end{array}$ \\
\hline A toler-finishes (L) B & $\begin{array}{l}\mathrm{A}^{\mathrm{L}} \text { overlapped_by } \\
\mathrm{B}_{\mathrm{L}} \wedge \mathrm{A}_{\mathrm{L}} \text { during } \mathrm{B}^{\mathrm{L}}\end{array}$ & $\begin{array}{l}\operatorname{Min}\left(d\left(\tilde{a}^{\mathrm{L}}>\tilde{b}_{\mathrm{L}}\right), \mathrm{d}\left(\tilde{\mathrm{b}}_{\mathrm{L}}^{\prime}>\tilde{\mathrm{a}}^{\mathrm{L}}\right),\right. \\
\left.\mathrm{d}\left(\tilde{\mathrm{a}}^{\prime}{ }^{\mathrm{L}}>\tilde{\mathrm{b}}_{\mathrm{L}}^{\prime}\right), \mathrm{d}\left(\tilde{\mathrm{a}}_{\mathrm{L}}>\tilde{\mathrm{b}}^{\mathrm{L}}\right), \mathrm{d}\left(\tilde{\mathrm{b}}^{\prime \mathrm{L}}>\tilde{\mathrm{a}}_{\mathrm{L}}^{\prime}\right)\right)\end{array}$ \\
\hline
\end{tabular}




\section{FUZZ-TIME SYSTEM}

\subsection{Architecture Overview}

Here we give an overview of Fuzz-TIME system. It includes in fact two main steps and each step contains a set of modules.

Step 1 begins with a temporal gradual query proposed by the user through a GUI of the FuzzTIME system. The latter requests the user to define a validity interval for each fuzzy temporal specification. Then, TSQLf query is generated and sent to a main interpretation module. This module is composed by a set of submodules; each presents an alternative for managing TSQLf queries. The result of this module corresponds to an evaluation of an SQL-like query.

The second step firstly proceeds to pass the query by reasoning module. The latter uses the inference machinery of fuzzy Allen relations. Then the request goes through the data management system to select rows that meet the required temporal criteria. Finally, the selected lines pass through the module of our system that calculates the degree of satisfaction of each line with the selection criteria. Then, the selected lines with their degrees are displayed to the user.

\subsection{Modules Description}

In [10] we have proposed an extension, named TSQLf, of $S Q L f$ language [11] by adding the time dimension. TSQLf language allows for expressing user queries involving fuzzy criteria on time.

It is founded on the fuzzy extension of temporal Allen relations already proposed in [2]. We have implemented this language and developed a first version of the Fuzz-TIME ${ }^{3}$ system.

In this preliminary version of Fuzz-TIME, queries involving fuzzy temporal criteria can be handled where the temporal relations can be defined in a fuzzy way but time are defined only in terms of regular (crisp) intervals. While in real-life applications, time intervals are often described by ill-defined bounds to better capture the vagueness inherent to the available pieces of time information. For this reason, in this work, we have introduced tolerant temporal relations to deal with this issue. Also, we have endowed our Fuzz-TIME Tool with the capabilities for handling such novel temporal relations.

First, we present the architecture of Fuzz-TIME system. Figure 5 depicts the different modules necessary to processing an TSQLf query. In the Interface module, the user enters a gradual temporal query using a graphical interface, this latter gives him/her in the first place the possibility of choosing attributes, tables and built fuzzy temporal conditions, and second the system asks the user to identify the validity interval and the tolerance interval for each fuzzy temporal condition (i.e., the fuzzy parameter L).

- If the user provides a validity interval with crisp bounds, then Fuzzy Allen Relation module (denoted by FAR) is triggered. More details about this module can be found in [10]. Note that in the case where the TSQLf query requires a phase of reasoning, the system calls the module Reasoning Step. This module leverages the inference machinery of fuzzy Allen relations developed in the first version.

\footnotetext{
${ }^{3}$ Fuzz-TIME: Fuzzy Temporal Information Managing and Exploitation.
} 
- If the user gives a validity interval with fuzzy bounds, then the system automatically computes the eroded and dilated intervals. Thereafter, the system passes the request to the Query Interpretation module which transforms the request into a crisp query using the Tolerant Allen Relations module (denoted by TAR) using the principle of dilation and erosion operations. The result of this module is an TSQLf query to be sent to the management system database in order to select the attributes that meet the fuzzy temporal query criteria.

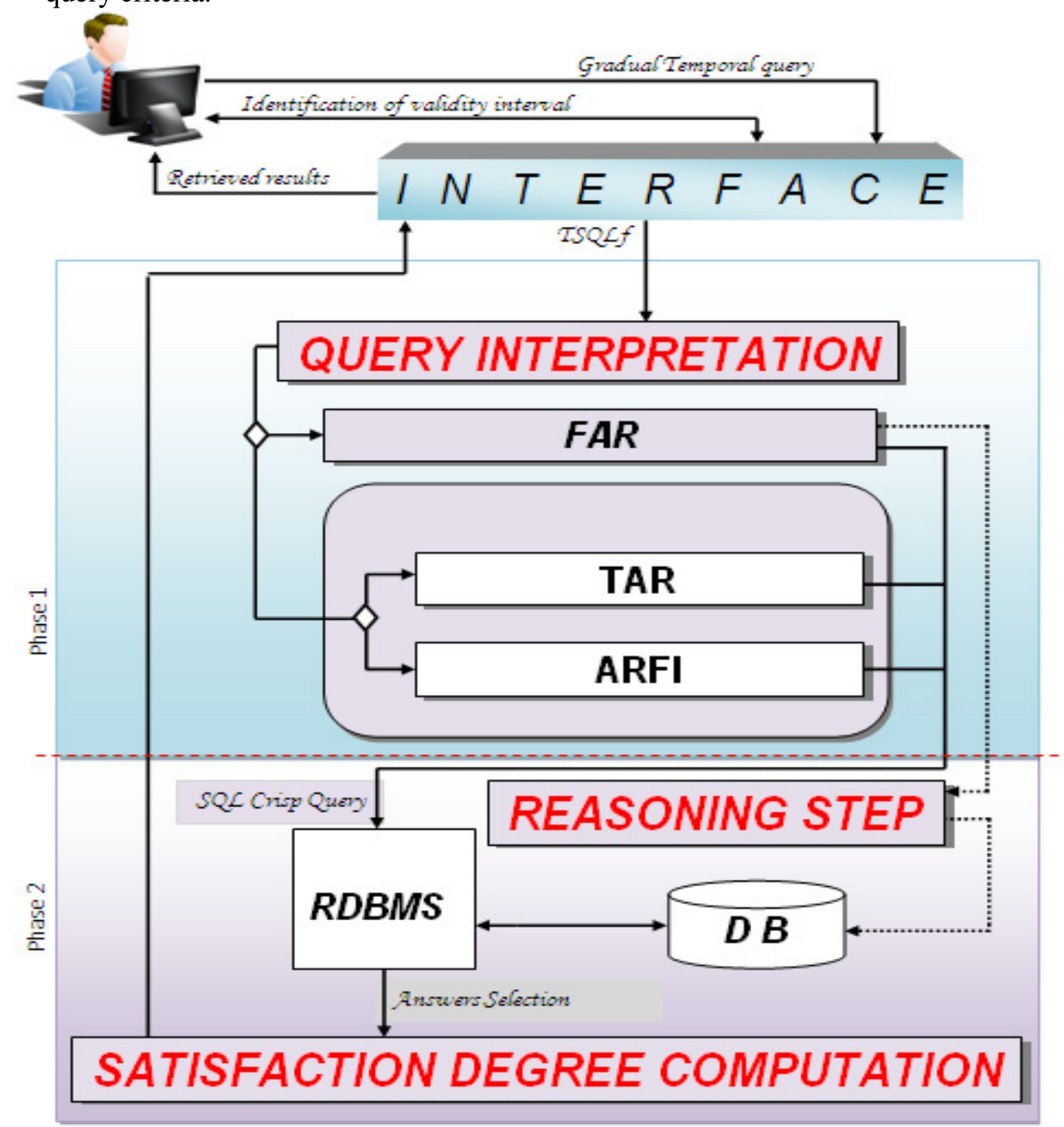

Figure 5. Architecture of Fuzz-TIME system.

The last module, Satisfaction Degree Computation, ensures the calculation of satisfaction degree of the TSQLf query at hand. The returned results are attached with a degree of satisfaction and then displayed on the user interface. 


\subsection{An Illustrative Example}

To better explain our proposal we present below an example from Archaeology field. Consider the Archaeology table (see Table 3) presenting the material remains from prehistoric times. The table schema is Archaeology (Code_Ar\#, Name_Ar, Location, Date_Discovery, VST_Dc, $\left.V E T \_D c, D a t e \_D a t e d, V S T \_D d, V E T \_D d\right)$. Where VST_Dc means the start validity date of Date Discovery, VET_Dc means the end validity date of Date_Discovery, VST_Dd means the start validity date of Date_Dated and VET_Dd means the end validity date of Date_Dated.

Table 3. The Archaeology table.

\begin{tabular}{|c|c|c|c|c|c|c|c|c|}
\hline Code_Ar & Name_Ar & Location & $\begin{array}{c}\text { Date_ } \\
\text { Discovery }\end{array}$ & VST_Dc & VET_Dc & Date_Dated & VST_Dd & VET_Dd \\
\hline A011 & $\begin{array}{l}\text { Pyramid of } \\
\text { six meters } \\
\text { in height }\end{array}$ & Lima & Recently & $10 / 07 / 2013$ & $31 / 07 / 2013$ & $\begin{array}{c}5000 \text { years } \\
\text { ago }\end{array}$ & $2987 \mathrm{BC}$ & $2988 \mathrm{BC}$ \\
\hline A015 & Cone rocks & $\begin{array}{c}\text { Lake } \\
\text { Tiberias }\end{array}$ & In 2003 & $05 / 02 / 2003$ & $08 / 08 / 2003$ & $\begin{array}{c}2050 \text { years } \\
\text { ago }\end{array}$ & $37 \mathrm{BC}$ & $38 \mathrm{BC}$ \\
\hline $\mathrm{A} 120$ & Church & $\begin{array}{c}\text { Island of the } \\
\text { City }\end{array}$ & Little ago & $20 / 06 / 2013$ & $25 / 07 / 2013$ & End 158 & $08 / 09 / 158$ & $18 / 12 / 158$ \\
\hline $\mathrm{A} 002$ & $\begin{array}{c}\text { Chanel } \\
\text { monumental }\end{array}$ & Narbanne & In 2010 & $05 / 03 / 2010$ & $10 / 11 / 2010$ & $\begin{array}{c}2455 \text { years } \\
\text { ago }\end{array}$ & $440 \mathrm{BC}$ & $442 \mathrm{BC}$ \\
\hline $\mathrm{A} 020$ & $\begin{array}{l}\text { Hunting } \\
\text { weapon }\end{array}$ & $\begin{array}{l}\text { South } \\
\text { Africa }\end{array}$ & Early 2009 & $03 / 01 / 2009$ & $05 / 04 / 2009$ & $\begin{array}{c}500000 \\
\text { years ago }\end{array}$ & $497985 \mathrm{BC}$ & $497987 \mathrm{BC}$ \\
\hline $\mathrm{A} 042$ & $\begin{array}{l}\text { Mammoth } \\
\text { Skeleton }\end{array}$ & $\begin{array}{l}\text { Seine-et- } \\
\text { Marne }\end{array}$ & $\begin{array}{l}\text { Summer } \\
2013\end{array}$ & $05 / 06 / 2013$ & $01 / 09 / 2013$ & $\begin{array}{c}\text { Before } \\
\text { beginning } \\
159\end{array}$ & $15 / 11 / 189$ & $13 / 12 / 189$ \\
\hline $\mathrm{A} 075$ & $\begin{array}{c}\text { Sort of } \\
\text { mini- } \\
\text { dinosaur }\end{array}$ & Africa & $\begin{array}{c}\text { October } \\
2012\end{array}$ & $02 / 10 / 2012$ & $31 / 10 / 2012$ & $\begin{array}{l}\text { Before the } \\
\text { end of } 260\end{array}$ & $20 / 09 / 260$ & $15 / 12 / 260$ \\
\hline A101 & $\begin{array}{l}\text { Indian } \\
\text { prints }\end{array}$ & Brazil & $\begin{array}{l}\text { Before the } \\
\text { end of } \\
\text { November } \\
2011\end{array}$ & $18 / 11 / 2011$ & $30 / 11 / 2011$ & $\begin{array}{c}\text { More than } \\
3000 \text { years } \\
\text { BC }\end{array}$ & $3000 \mathrm{BC}$ & $3002 \mathrm{BC}$ \\
\hline A111 & $\begin{array}{c}\text { Corps } \\
\text { soldiers } \\
\text { Allemends }\end{array}$ & Carspach & $\begin{array}{l}\text { Before the } \\
\text { end of } 2011\end{array}$ & $12 / 10 / 2011$ & $15 / 12 / 2011$ & In 1918 & $10 / 07 / 1918$ & $15 / 12 / 1918$ \\
\hline A 224 & $\begin{array}{l}\text { Statues } \\
\text { banned by } \\
\text { the Nazis }\end{array}$ & Berlin & $\begin{array}{c}\text { Beginning } \\
\text { in } \\
\text { November } \\
2010\end{array}$ & $01 / 11 / 2010$ & $10 / 11 / 2010$ & $\begin{array}{l}\text { During the } \\
\text { second war } \\
\text { mandial }\end{array}$ & $01 / 09 / 1939$ & $02 / 09 / 1945$ \\
\hline
\end{tabular}

\subsection{Demonstrative Scenarios}

We will demonstrate the functioning of our Fuzz-TIME system by presenting some particular queries over archaeological databases.

- Q1: Show archaeological discoveries that took place during the 3rd quarter of 2000.

Here the user asked a query with a fuzzy temporal condition (3rd quarter) but we can easily interpret the validity interval of the fuzzy temporal condition corresponding to [01/07/2000, 30/09/2000]. So the solution is a simple SQL query.

\section{Select *}

From Archaeology A

Where A.VST > 01/07/2000 and A.VET < 30/09/2000;

- Q2: Show archaeological discoveries that took place just after the Second World War.

The user indicated in this query a fuzzy temporal constraint (Second World War). So we must proceed with the generation of a TSQLf request. According to the principle of TSQLf query, the 
system must ask the user to specify a valid interval for fuzzy temporal constraint proposed by the user. Indeed two cases are possible here:

i) the user can define a validity interval with two crisp bounds [VST, VET]. For example [01/09/1939, 02/09/1945]

So here we use the first principle of the TSQLf approach and the request will be

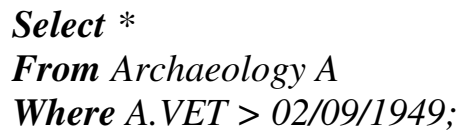

ii) the user can define a validity interval with two fuzzy bounds [VST, VET]. For example [Before the end of 1939, Just before end of 1945]

So the bounds of validity interval defined by the user are fuzzy, consequently $T S Q L f$ query should use the principle of Tolerant Allen Relations; the system asks the user to define a fuzzy set $A=\left(a, a^{\prime}, \alpha, \alpha^{\prime}\right)$ for the validity fuzzy interval and a fuzzy set $L=(-\delta, \delta, \varepsilon, \varepsilon)$. For example: $A=(20 / 09 / 1939,10 / 09 / 1945,7,5)$ and $L=(-3,3,2,1)$. Then the system generates automatically two intervals the eroded and dilated ones. Thereafter it generates a TSQLf query using Tolerant Allen Relations proposed in section 3. 2.

\subsection{Implementation and Interface}

We present in this section some user-friendly interfaces that help to make gradual temporal queries based on tolerant Allen relations. It can help users for expressing temporal terms in a fuzzy way. The tool we have developed acts as an JAVA interface with the Oracle DBMS and generates TSQLf queries directly executable by calls to functions and PL/SQL bloc stored. The interface is connected to the database so as to store the tables in the field study that incorporates fuzzy temporal aspects. In this way, it is possible to add for each table, which contains a crisp/fuzzy temporal attribute, two specific temporal attributes (VST, VET).

Our first approach proposed in [10] is still functional in our Fuzz-TIME system, Figure 6 shows the possibility that a user can enter a query with a temporal fuzzy constraint then he can define the validity interval with two crisp dates.

The extension integrated in Fuzz-TIME tool allows, first, to accept the definition of fuzzy temporal condition (Figure 7), and second, the definition of validity interval and tolerance interval for each fuzzy temporal condition. Here the user can introduce fuzzy bounds for each validity intervals (Figure 7). 


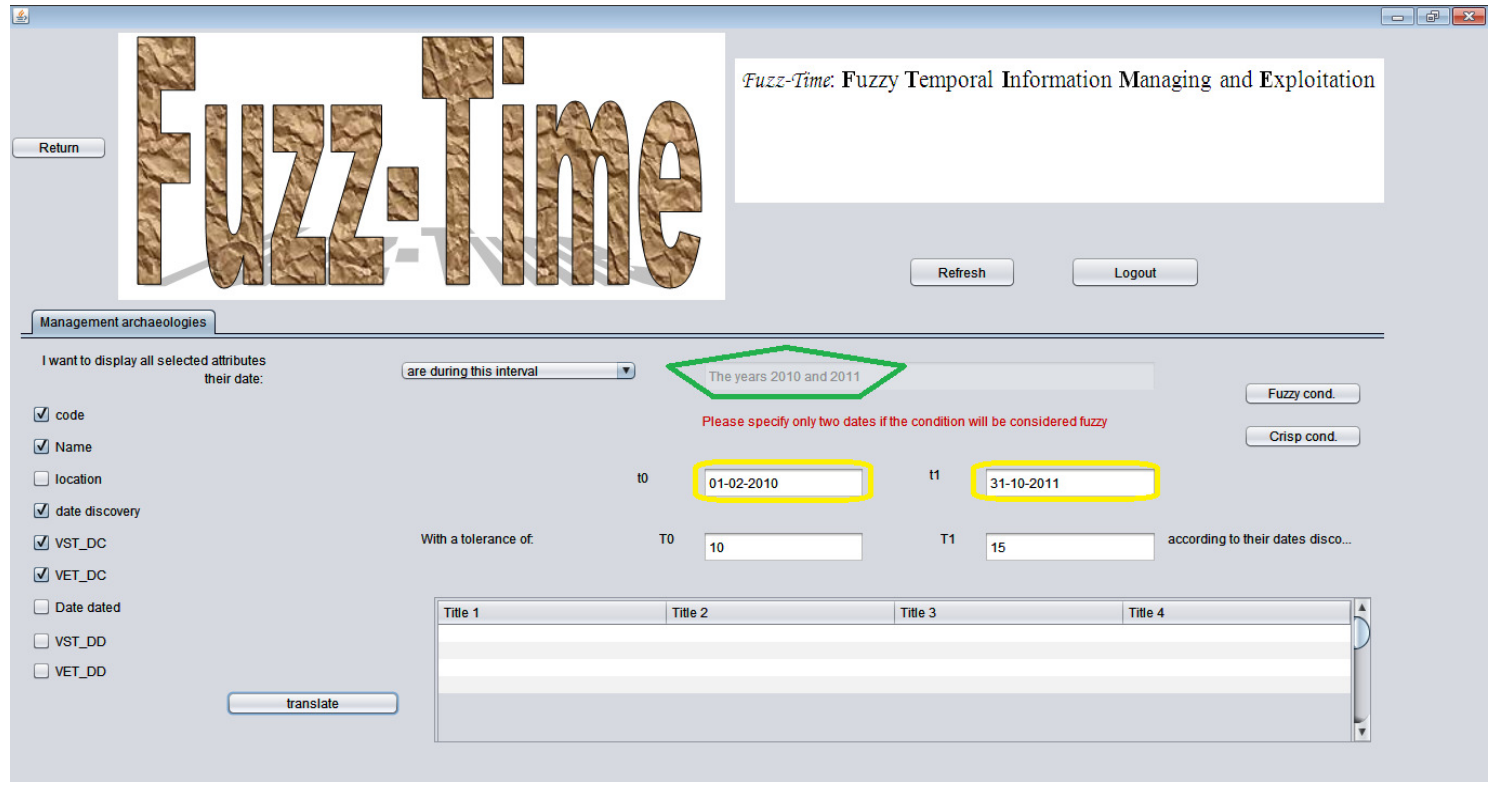

Figure 6. Definition of fuzzy temporal conditions with crisp bounds.

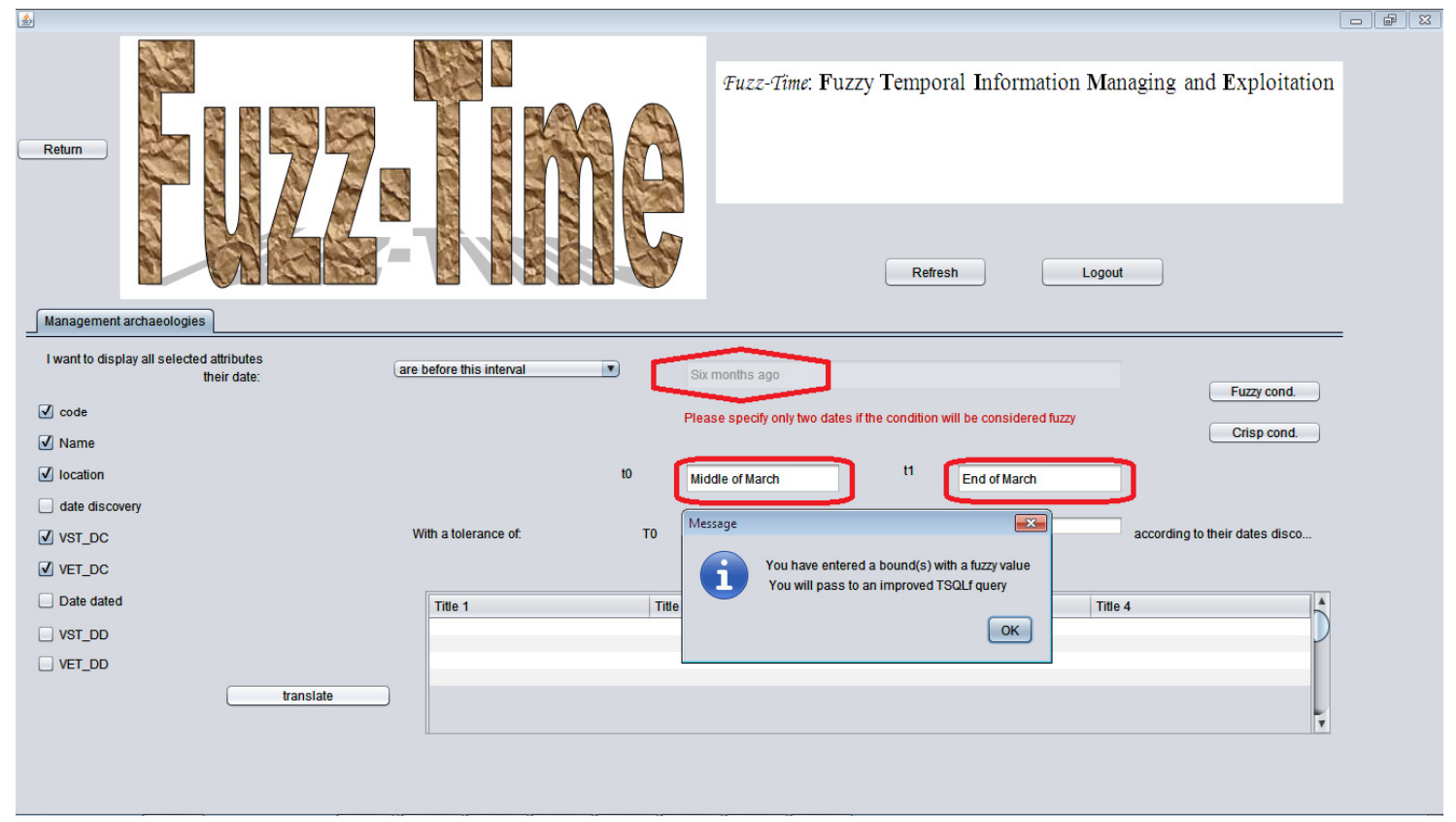

Figure 7. Definition of fuzzy temporal conditions.

After the step above, the tool informs the user that the bounds introduced are fuzzy so it is necessary to define the fuzzy set $A$ corresponding to a fuzzy temporal condition as well as the fuzzy set $L$. The aim is to generate automatically the pair intervals (dilated and eroded ones). Then, the generated TQSLf query is submitted to the database to select rows that match its fuzzy temporal criteria. Finally, a degree of satisfaction is calculated and assigned to each selected line (Figure 8 and Figure 9). 


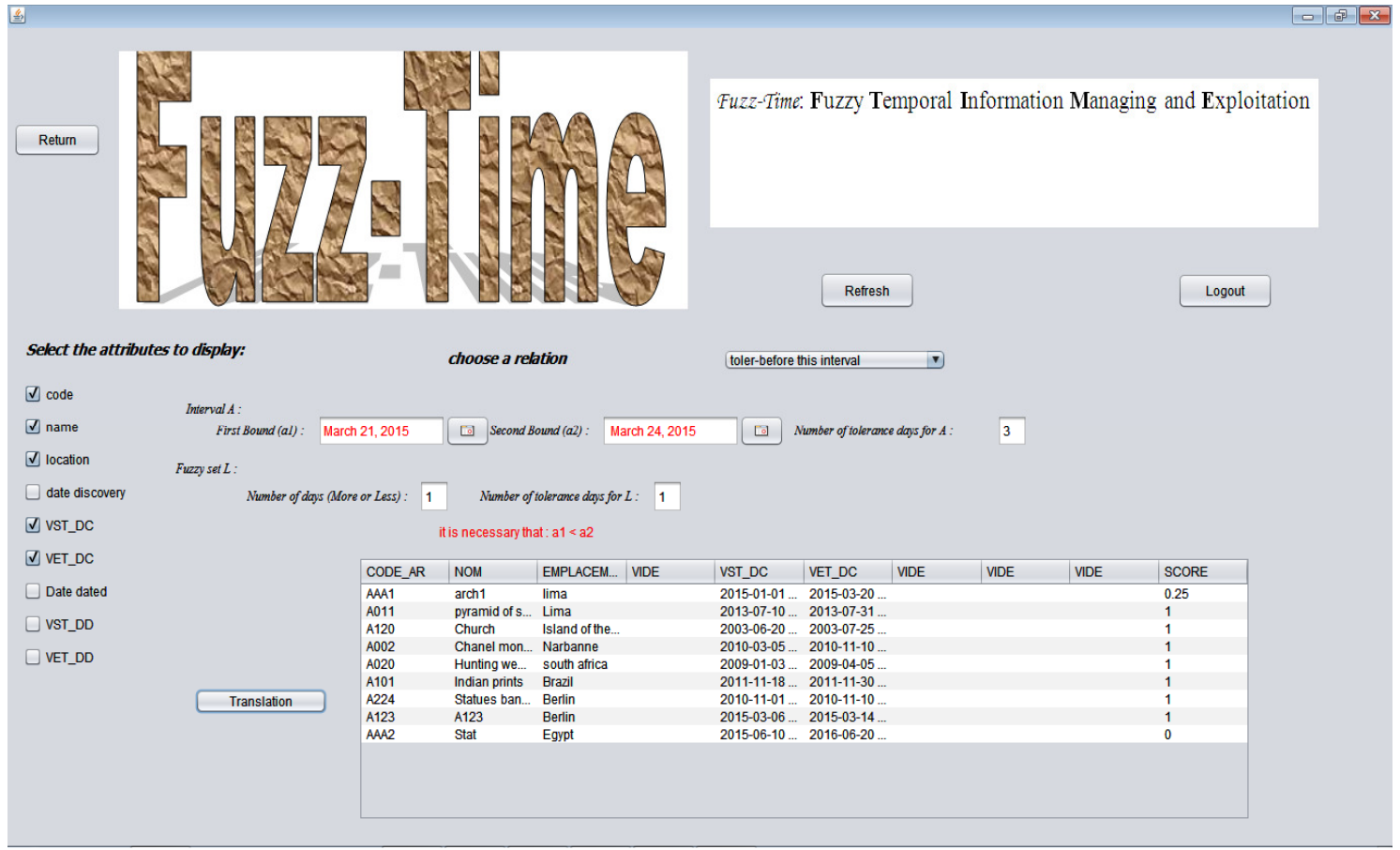

Figure 8. Result of an TSQLf query.

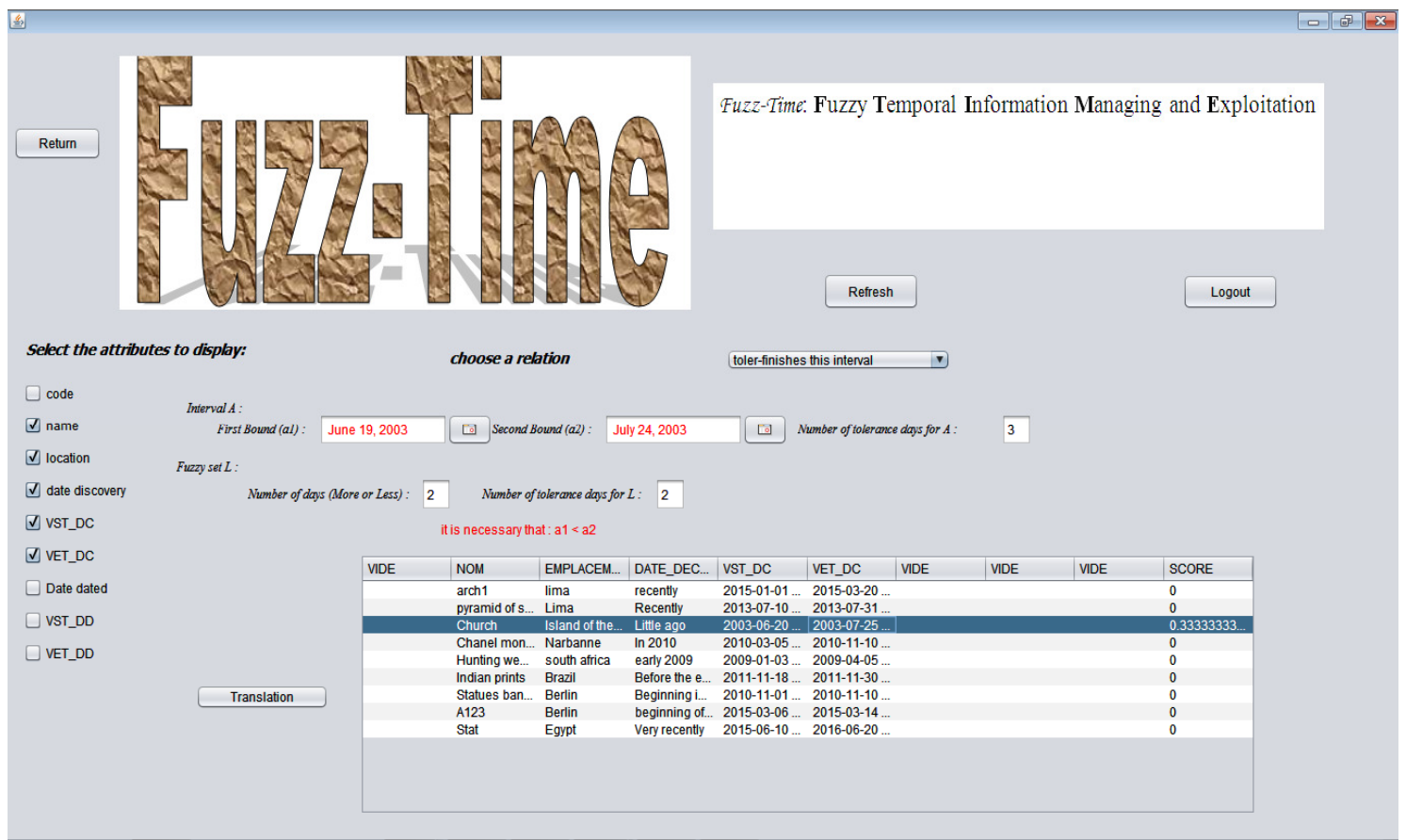

Figure 9. Result of an TSQLf query 


\section{CONCLUSION}

In this paper, we have defined the principle of tolerance-based of Allen temporal relations to manage time intervals with fuzzy bounds. The key notion of this extension is the dilation and erosion operations defined on fuzzy time intervals. Then we have defined a way for computing such introduced relations by leveraging fuzzy indices comparison. A new version of our FuzzTIME System is developed. It allows handling temporal queries where time can be expressed in terms of fuzzy intervals.

As for future immediate work, we first plan to establish the complete set of composition rules of the tolerant Allen relations for the purpose of reasoning and inference. Second, we incorporate such reasoning in our Fuzz-TIME System. Another line of future research is to investigate the issue of uncertainty in temporal relations in the spirit of [25].

\section{REFERENCES}

[1] C. Billiet \& G. De Tré, (2015) "The Role of Computational Intelligence in Temporal Information Retrieval: A Survey of Imperfect Time in Information Systems”, In Proc. of the 13th International Conference on Flexible Query Answering Systems (FQAS'2015), Vol. 400, pp. 41-756.

[2] D. Dubois, A. Hadjali, \& H. Prade, (2003) 'Fuzziness and uncertainty in temporal reasoning', Journal of Universal Computer Science, Special Issue on Spatial and Temporal Reasoning, Vol. 9, pp. 1168-1194.

[3] S. Schockaert \& M. De Cock, (2008) "Temporal reasoning about fuzzy intervals", Artificial Intelligence, Vol. 172, pp. 1158-1193.

[4] S. Badaloni \& M. Giacomin, (2006) "The algebra IAfuz: a framework for qualitative fuzzy temporal", Artificial Intelligence, Vol. 170 (10), pp. 872-902.

[5] C. Billiet, J. E. Pons, T. Matthe, G. De Tré, \& O. P. Capote, (2011) "Bipolar fuzzy querying of temporal databases", In Proc. of the 9th International Conference on Flexible Query Answering Systems (FQAS'2011), Springer Berlin Heidelberg, Vol. 7022, pp. 60-71.

[6] F. Pons, C. Billiet, O. Pons, G. De Tré, (2014) "Aspects of dealing with imperfect data in temporal databases". In: Pivert, O., Zadrózny, S. (eds.) Flexible Approaches in Data, Information and Knowledge Management, Springer, Heidelberg, Vol. 497, pp. 189-220.

[7] L. Deng, Z. Liang, \& Y. Zhang, (2008) "A fuzzy temporal model and query language for fter databases", 8th International Conference on Intelligent Systems Design and Applications, Vol. 3, pp. $77-82$

[8] C. Tudorie, M. Vlase, C. Nica, \& D. Muntranu, (2012) "Modeling fuzzy temporal criteria in database querying', Artificial Intelligence Applications, Vol. 112, pp. 1-6

[9] J. Galindo \& J.M.Medina, (2001) "Ftsq12 : Fuzzy time in relational databases", Proc. of the 2nd International Conf. in Fuzzy Loggic and Technology, pp. 5-7

[10] A. Gammoudi, A. Hadjali, \& B B. Yaghlane, (2014) "An intelligent flexible querying approach for temporal databases", Proc. of the 7th international Conference on Intelligent Systems IS'14, Vol. 322, pp. 523-534.

[11] O. Pivert \& P. Bosc, (2012) "Fuzzy Preference Queries to Relational Databases", Imperial College Press, pp. 330

[12] J. F. Allen, (1983) "Maintaining knowledge about temporal intervals", Comm. of the ACM, Vol. 26, pp. 832-843

[13] D. Dubois \& H. Prade, (1988) "Possibility theory", Plenum Press.

[14] D. Dubois \& H. Prade, (1983) "Inverse operations for fuzzy numbers", Proc. IFAC Symp. on Fuzzy Info., Knowledge representation and Decision Analysis, pp. 391-395.

[15] D. Dubois \& H. Prade (1989) "Processing fuzzy temporal knowledge", IEEE Trans. On Systems, Man and Cybernetics, Vol. 19, pp. 729-744. 
[16] H. W. Guesgen, J. Hertzberg, \& A. Philpott, (1994) "Towards implementing fuzzy allen relations", Proc. ECAI-94 Workshop on Spatial and Temporal Reasoning, Amsterdam, The Netherlands, pp. 4955.

[17] D.Q. Qian \& Y.Z. Lu, (1989) “A strategy of problem solving in a fuzzy reasoning network”, In Fuzzy Sets and Systems, Vol. 33, pp. 137-154.

[18] S. Barro, R. Marin, J. Mira, \& A. Paton, (1994) "A model and a language for the fuzzy representation and handling of time", In Fuzzy Sets and Systems, Vol. 31. pp. 153-175.

[19] L. Godo \& L. Vila, (1995) "Possibilistic temporal reasoning based on fuzzy temporal constraints", In Proc. of the 14th Inter. Joint Conf. on Artificial Intelligence (IJCAI'95), Montral, Vol. 2, pp. 19161922.

[20] D. Dubois, J. Lang, \& H. Prade (1991), "Timed possibilistic logic", In Fundamentae Informaticae, Vol. 15, pp. 211-234.

[21] A. Gammoudi, A. Hadjali, \& B B. Yaghlane, (2015) "A Tolerance-Based Semantics of Temporal Relations: First Steps", Proc. of the 7th International Conference on Computational Collective Intelligence Technologies and Applications ICCCI'15, Spring Vol. 9329, pp. 453-462.

[22] G. Nagypal \& B. Motik, (2003) "A fuzzy model for representing uncertain, subjective, and vague temporal knowledge in ontologies", On The Move to Meaningful Internet Systems 2003: CoopIS, DOA, and ODBASE, LNCS, Vol. 2888, pp. 906-923

[23] H. Ohlbach (2004), "Relations between fuzzy time intervals". Proc. of the 11th International Symposium on Temporal Representation and Reasoning, pp. 44-51

[24] D. Dubois \& H. Prade, (1983) "Ranking fuzzy numbers in the setting of possibility theory", Informations Sciences, Vol. 30, pp. 183-224.

[25] N. El Hadj Salem, A. Hadjali, B. B. Yaghlane \& A. Gammoudi, (2015) "An Evidential Approach to Managing Temporal Uncertainty", Proc. of the 24th French Conference on Fuzzy Logic and its Applications, LFA'15, Poitiers, France, pp. 243-249. 